\title{
Calcified cephalohematoma as an unusual cause of EEG anomalies: case report
}

\author{
Vera Vigo, MD, ${ }^{1}$ Domenica Immacolata Battaglia, MD, ${ }^{2}$ Paolo Frassanito, MD, ${ }^{1}$ \\ Gianpiero Tamburrini, MD, ${ }^{1}$ Massimo Caldarelli, MD, ${ }^{1}$ and Luca Massimi, MD, PhD ${ }^{1}$ \\ Departments of ${ }^{1}$ Pediatric Neurosurgery and ${ }^{2}$ Pediatric Neurology, A. Gemelli Hospital, Rome, Italy
}

Cephalohematoma, one of the most common neonatal head injuries, generally undergoes spontaneous resorption. When calcified, it may cause cranial vault distortion and depression of the inner skull layer, although it remains asymptomatic. Surgery, indeed, is usually performed for cosmetic purposes. For these reasons, the long-term effects of calcified cephalohematoma (CC) are widely unknown.

The authors report the case of an 11-year-old girl with a persistent calcified CC causing skull deformity and delayed electroencephalography (EEG) anomalies. These anomalies were detected during routine control EEG and were not clinically evident. The young girl underwent surgical removal of the CC for cosmetic purpose. The EEG abnormalities disappeared after surgery, thus reinforcing the hypothesis of a correlation with the brain "compression" resulting from the CC. To the best of the authors' knowledge this is the first time that CC-associated EEG anomalies have been described: even though these anomalies cannot be considered an indication for surgery, they merit late follow-up in case of skull deformity.

http://thejns.org/doi/abs/10.3171/2016.6.PEDS16120

KEY WORDS calcified cephalohematoma; cranial injury; newborn; electroencephalogram; trauma

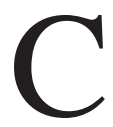

EPHALOHEMATOMA represents the most frequent cranial injury in the newborn, occurring in $0.2-2.5 \%$ live births. ${ }^{30}$ It arises from the breaking of small pericranium veins during delivery (prolonged labor, and the use of forceps and a vacuum extractor) resulting in a collection of blood below the periosteum of the skull. In about 3\%-5\% of cases, such a blood collection fails to resorb, leading to a calcified cephalohematoma (CC) ${ }^{29} \mathrm{Be}-$ cause of the flexible shape of the neonatal skull, when the hematoma expands and becomes sufficiently thick, it can encroach upon the cranial vault space..$^{29}$ Generally, the CC does not cause neurological sequelae. ${ }^{20}$ Moreover, clinical sequelae, in contrast to esthetic effects, are rarely reported. ${ }^{29}$ However, sagittal synostosis secondary to cephalohematoma has been described. . $^{11,15,16}$

We report the case of an 11-year-old girl with a CC that caused late-onset cerebral electrical anomalies. To the best of our knowledge, this complication was not been described to date in the literature.

\section{Case Report}

This 11-year-old girl was born after a forceps-assisted vaginal delivery resulting in a bilateral parietal cephalohematomas. The left cephalohematoma gradually resorbed within the 1st month of life, whereas the right one became calcified; no operation was advised at that time. The young girl grew up without any relevant physical and psychomotor problems. However, she had some learning disabilities (writing and reading) associated with a mild attention deficit diagnosed based on neuropsychological testing. For this reason, she received serial electroencephalography (EEG) studies over time that did not show abnormalities. The last EEG study obtained during the follow-up (when the girl was 10 years old), however, showed posterior asymmetrical alpha activity in the background, with low amplitude on the right side and sporadic right frontoparietal shapes (Fig. 1). Therefore, brain MRI was performed that revealed a right parietal cephalohematoma (thickness 
$25 \mathrm{~mm}$ ), with alteration of the inner layer of the skull and moderate brain parenchyma compression (Fig. 2). A new EEG study, performed 3 months later, showed the persistence of the same abnormalities of the previous study.

The patient was then admitted to our institution for neurosurgical treatment of the cephalohematoma, mainly for cosmetic purposes. At admission, she was in good clinical condition; physical examination did not indicate the presence of any neurological deficits. She complained of mild headache. We did observe a gross bony protuberance overlying the parietal area on the right side. After induction of general anesthesia (sevoflurane and remifentanil), a circular craniotomy was made and the $\mathrm{CC}$ was removed. Bone remodeling of both the inner and the outer surface of the bone flap to thin it out was performed using highspeed drilling.

The patient's postoperative course was uneventful. The pathological report confirmed the diagnosis of CC (remodeled bone with calcified blood remnants). MRI showed the bone remodeling and the subsequent brain decompression (Fig. 3). EEG studies demonstrated the disappearance of the electric abnormalities in the right hemisphere 6 months after surgery (Fig. 4) and at the latest follow-up (12 months). No significant changes in the patient's learning disabilities and attention deficit were observed on neuropsychological tests performed 6 months after surgery.

\section{Discussion}

Cephalohematoma usually starts as a fluctuant mass covering the parietal bone during the first $24-72$ hours after the birth; it then becomes firm and tense and is completely resorbed from within 2-4 weeks to 3-4 months. In rare cases (3\%-5\%), it fails to resorb and induces a progressive sub-pericranial osteogenesis that results in a CC. ${ }^{21,29}$ What underlies the failure for the mass to resorb is not yet known. ${ }^{19}$ The calcification process begins when a ridge forms along the periphery of the hematoma, causing a distortion of the calvaria. Calcified cephalohematoma can be classified as Type 1 or 2, based on the contour of the inner lamella. In Type $1 \mathrm{CC}$, the inner bone is not involved and there is no encroachment into the cranial cavity. In contrast, Type $2 \mathrm{CC}$ exhibits a depression of the inner bone that pushes into the cranial cavity. In spite of the encroachment occurring in Type 2, there are no reports on a CC causing focal neurological deficits or raised intracranial pressure, ${ }^{16,29}$ probably because its growth is slow enough to allow the nervous structures of the newborn to accommodate the mass. ${ }^{29}$ Even if asymptomatic, the cephalohematoma can hide a skull fracture along with underlying epidural hematoma or intracranial hemorrhage, thus justifying the recommendation of transfontanellar ultrasound by some authors. ${ }^{14,22}$

In a recent study, Swanson et al. reported on children presenting with nonsyndromic craniosynostosis who had a higher risk of birth trauma (both for mother and fetuses), such as subgaleal and subperiosteal perinatal bleeding. ${ }^{24}$ In the past, some authors have argued that $\mathrm{CC}$ can cause scaphocephaly in some instances,,, 16 leading to the premature closure of the sagittal suture, although at histological

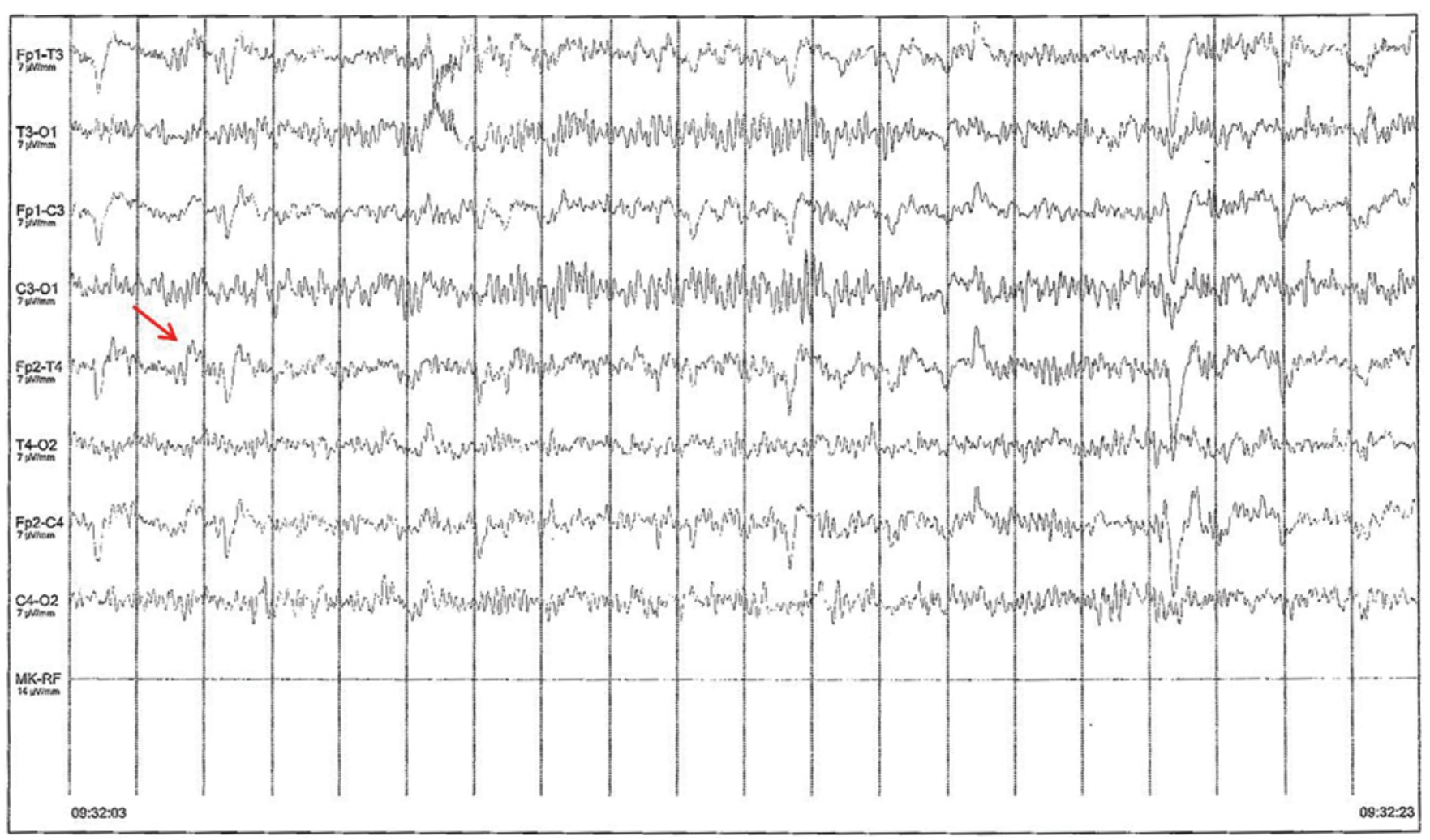

FIG. 1. Preoperative EEG showing asymmetry of the background activity and sporadic spikes on the right side (arrow). Figure is available in color online only. 

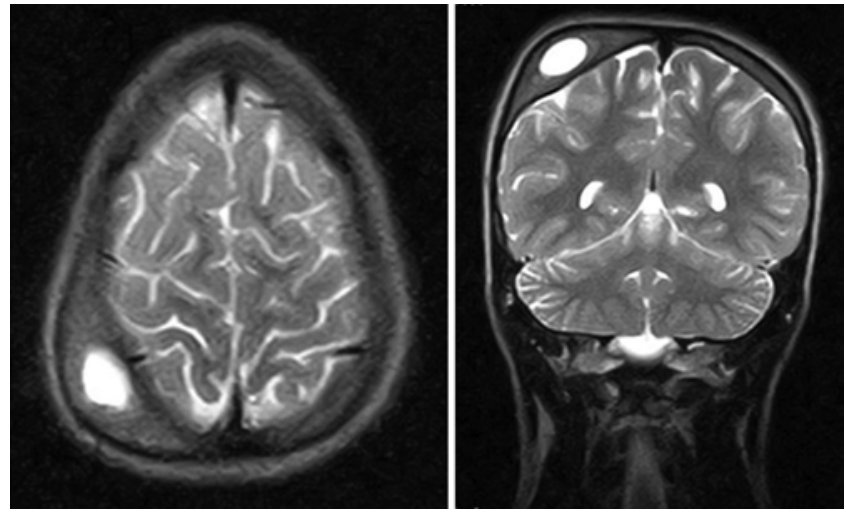

FIG. 2. Preoperative T2-weighted axial and coronal MR images showing the right $\mathrm{CC}$ with mass effect on the frontoparietal brain.

examination has not detected suture formation underlying the CC. Other authors have shown that the midline location of cephalohematoma occurs only in the case of sagittal craniosynostosis. ${ }^{11,17}$

The long-term effects on the brain of $\mathrm{CC}$ encroaching into the cranial vault are unknown. A unique aspect of the present case is the occurrence of a possible late-onset neurological complication of the cephalohematoma. To the best of our knowledge, our report is the first to describe the long-term effects of $\mathrm{CC}$, and the case shows that the long-lasting compression of the cephalohematoma on the dural layer and the cortex may cause abnormality of the brain activity on EEG. The surgical decompression was able to resolve such activity, although the follow-up dura-
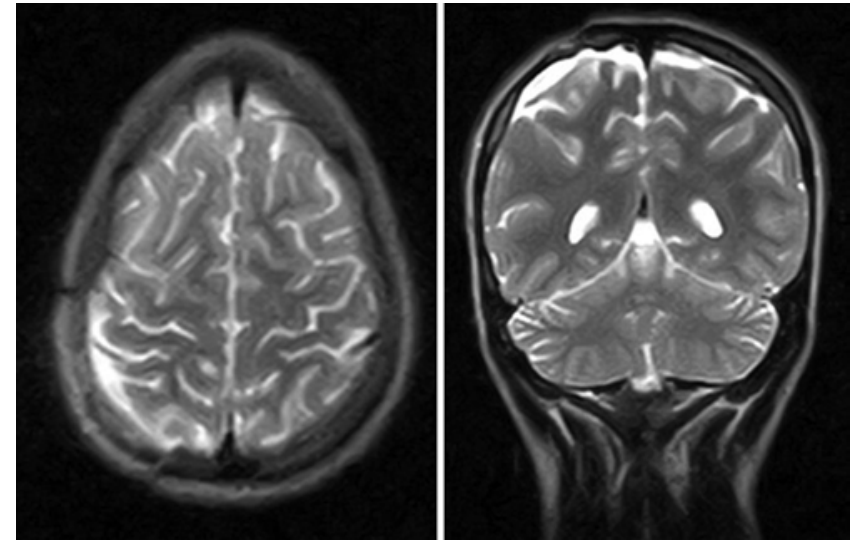

FIG. 3. Postoperative T2-weighted axial and coronal imaging MR images, acquired 1 month after surgery, demonstrating the removal of the cephalohematoma and the mass effect resolution.

tion is still too short to consider this result as definitive. In our opinion, this is not enough to raise the question of treating all thick CCs, but it should suggest that untreated patients should be monitored with repeated EEG over the time. This kind of follow-up represents only a little change in the clinical practice but could be enough to detect early electric abnormalities resulting from brain irritation. Actually, EEG is usually easily manageable in children. On the other hand, more "invasive" investigations, like PET scanning or magnetoencephalography, can be used to refine the diagnostic assessment (especially in doubtful cases) and/or to look for possible changes after surgery.

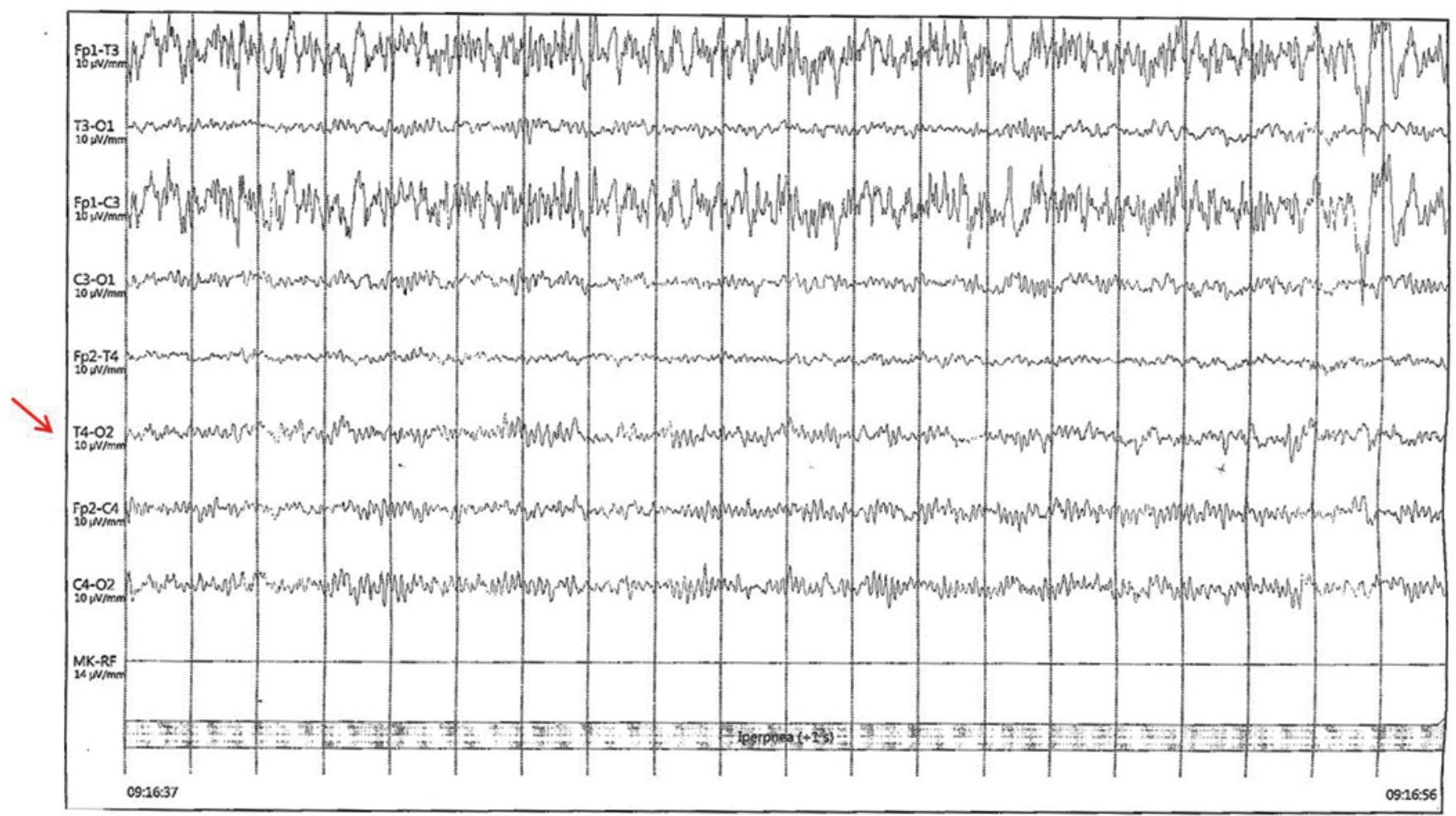

FIG. 4. Postoperative EEG (6 months later the preoperative one) demonstrating the absence of the previous right anomalies (arrow). Figure is available in color online only. 
A well-known consequence of traumatic brain injury (TBI) is posttraumatic seizure. Depending on their time of onset after TBI, seizures can be classified as immediate (less 24 hours from trauma), delayed early (within 1 week), and late (more than 1 week). ${ }^{1}$ Many studies have been carried out to demonstrate the correlation between head injury and late posttraumatic epilepsy ${ }^{9}$ to settle on the timing of follow-up and treatment. After head injury, late posttraumatic seizures, both partial and generalized, can develop, usually from 1 week until 5 years.,25 Information on this issue is generally available in cases of depressed skull fractures or growing fractures; in fact, some authors have reported that early seizures and depressed skull fractures are the main risk factors for late posttraumatic epilepsy. ${ }^{1,25}$ Cases of delayed epilepsy (after more than 5 years from TBI) have been reported as a possible consequence of a growing skull fracture., ${ }^{7,10,23}$ The chronic irritation of the dura and the underlying brain may be the cause of late EEG anomalies (as in our case) or epileptic events. Basically, the relevance of these anomalies is hard to define since they are usually subclinical and do not require a specific drug treatments, but, at the same time, they are associated with the risk worsening over time and evolving into epileptic activity. Other authors, however, have not pointed out a significant correlation between depressed skull fractures and late posttraumatic seizures, ${ }^{9}$ nor between linear skull fracture and EEG abnormalities. ${ }^{12}$ This shows that a bone injury can be a cause of EEG abnormality, but it is probably associated with dural damage. As far as the other disabilities in our patient are concerned, although some of them could be correlated with the compression (namely, the attention deficit), no changes have occurred after surgery to date, thus suggesting no strict relationship with the cephalohematoma.

A second, infrequent finding presented by our case is the late appearance of a CC on MRI and at surgery. Usually, fluid cephalohematoma does not require neuroimaging investigations other than ultrasound, although it can hide intracranial hemorrhage ${ }^{14}$ or skull lesions with fluidfluid levels (such as Langerhans cell histiocytosis or aneurysmal bone cysts) ${ }^{18}$ or it can mimic an encephalocele. ${ }^{28}$ On the other hand, neuroimaging may be needed in $\mathrm{CC}$ to exclude a deformation of the inner cranial surface, for assessment of the type of lesion, and for operative planning (selection of appropriate reconstructive technique). Neuroimaging may be useful also to rule out alternative diagnoses, such as bone tumor or scalloping of the skull due to brain tumors/lesions. On MRI, cephalohematoma exhibits a bright signal on T1-weighted images and a predominantly high signal with mild heterogeneity on T2-weighted images, which depends on the presence of methemoglobin and indicates that the lesion as secondary to hemorrhage rather than to an intraosseous tumor. ${ }^{6,26,27} \mathrm{CT}$ is an alternative option for assessment of CCs, ${ }^{29}$ which appear as a uniformly homogeneous, hypodense, nonenhancing core encased by bone. Thanks to 3D reconstruction, CT can be very useful for preoperative planning in the selection of appropriate reconstructive technique.

The treatment of CC is still debated because of the lesion's benign clinical course. In neonates, only observation is suggested, because the cephalohematoma can be gradually absorbed as the skull develops. ${ }^{6,30}$ Some authors have proposed a passive cranial molding-helmet therapy as a successful nonsurgical treatment for CCs causing cranial asymmetry. ${ }^{20}$ An accepted indication for surgery is the correction of skull asymmetry for cosmetic reasons. ${ }^{3}$ Other indications may be the prevention of brain growth restriction, and diagnostic confirmation and treatment of associated craniosynostosis. ${ }^{11,13,15,16}$ Surgery is performed according to the features of the CC. Type I CC is treated by drilling of the outer lamella, whereas Type 2 is treated by craniotomy and cranioplasty. ${ }^{29}$ The intraoperative appearance of $\mathrm{CC}$ depends on the degree of calcification of the hematoma. ${ }^{4,8,29}$ In our case, the intraoperative appearance was characterized by an abnormal thickening of the skull; for this reason, a remodeling of the outer and inner lamella of the skull was performed, without using any prosthetic material.

\section{Conclusions}

Although quite common as a neonatal head injury, cephalohematoma rarely calcifies and even more rarely requires a surgical correction. No long-term effects of this disease are reported except for the cosmetic impact. Based on the present case, subclinical EEG anomalies may be considered as a late consequence of CC causing skull deformation and brain compression and deserving a specific follow-up in selected cases.

\section{References}

1. Asikainen I, Kaste M, Sarna S: Early and late posttraumatic seizures in traumatic brain injury rehabilitation patients: brain injury factors causing late seizures and influence of seizures on long-term outcome. Epilepsia 40:584-589, 1999

2. Chen JW, Ruff RL, Eavey R, Wasterlain CG: Posttraumatic epilepsy and treatment. J Rehabil Res Dev 46:685-696, 2009

3. Chung HY, Chung JY, Lee DG, Yang JD, Baik BS, Hwang SG, et al: Surgical treatment of ossified cephalhematoma. J Craniofac Surg 15:774-779, 2004

4. Chung KC, Buchman SR, Maher HA, Dauser RC: Surgical management of calcified cephalhematoma and associated skull defect in infancy. Ann Plast Surg 34:99-102, 1995

5. Currarino G: Neonatal subperiosteal cephalohematoma crossing a synostosed sagittal suture. Pediatr Radiol 37:1283-1285, 2007

6. Daglioglu E, Okay O, Hatipoglu HG, Dalgic A, Ergungor F: Spontaneous resolution of calcified cephalhematomas of infancy: report of two cases. Turk Neurosurg 20:96-99, 2010

7. Diyora B, Nayak N, Kamble H, Kukreja S, Gupte G, Sharma A: Surgical treatment and results in growing skull fracture. Neurol India 59:424-428, 2011

8. Gupta PK, Mathew GS, Malik AK, Al Derazi T: Ossified cephalhematoma. Pediatr Neurosurg 43:492-497, 2007

9. Hahn YS, Fuchs S, Flannery AM, Barthel MJ, McLone DG: Factors influencing posttraumatic seizures in children. Neurosurgery 22:864-867, 1988

10. Harvey K, Turner MR, Adcock J: Child neurology: a growing skull fracture. Neurology 72:e38, 2009

11. Kaiser GL, Oesch V: Sagittal craniosynostosis combined with ossified cephalhematoma-a tricky and demanding puzzle. Childs Nerv Syst 25:103-110, 2009

12. Karabudak R, Ciger A, Ertürk I, Zileli T: EEG and the linear skull fractures. J Neurosurg Sci 36:47-49, 1992

13. Kaufman HH, Hochberg J, Anderson RP, Schochet SS Jr, 
Simmons GM Jr: Treatment of calcified cephalohematoma. Neurosurgery 32:1037-1040, 1993

14. Kim HM, Kwon SH, Park SH, Kim YS, Oh KW: Intracranial hemorrhage in infants with cephalohematoma. Pediatr Int 56:378-381, 2014

15. Kortesis BG, Pyle JW, Sanger C, Knowles M, Glazier SS, David LR: Surgical treatment for scaphocephaly and a calcified cephalohematoma. J Craniofac Surg 20:410-413, 2009

16. Martinez-Lage JF, Esteban JA, Martinez Perez M, Poza M: Craniostenosis secondary to calcified subperiosteal hematoma: case report. Neurosurgery 15:703-704, 1984

17. Merlob P, Grunebaum M, Reisner SH: Crossed sagittalsuture cephalhaematoma. Br J Radiol 58:1007-1008, 1985

18. Nabavizadeh SA, Bilaniuk LT, Feygin T, Shekdar KV, Zimmerman RA, Vossough A: CT and MRI of pediatric skull lesions with fluid-fluid levels. AJNR Am J Neuroradiol 35:604-608, 2014

19. Nicholson L: Caput succedaneum and cephalohematoma: the Cs that leave bumps on the head. Neonatal Netw 26:277281, 2007

20. Petersen JD, Becker DB, Fundakowski CE, Marsh JL, Kane AA: A novel management for calcifying cephalohematoma. Plast Reconstr Surg 113:1404-1409, 2004

21. Plauché WC: Subgaleal hematoma. A complication of instrumental delivery. JAMA 244:1597-1598, 1980

22. Scheibl A, Calderón EM, Borau MJ, Prieto RM, González PF, Galiana GG: Epidural hematoma. J Pediatr Surg 47:e19-e21, 2012

23. Singla N, Gupta SK: The natural history of an untreated growing skull fracture: an unusual case. Pediatr Neurosurg 46:76-79, 2010

24. Swanson J, Oppenheimer A, Al-Mufarrej F, Pet M, Arakawa C, Cunningham M, et al: Maternofetal trauma in craniosynostosis. Plast Reconstr Surg 136:214e-222e, 2015

25. Temkin NR, Dikmen SS, Winn HR: Management of head injury. Posttraumatic seizures. Neurosurg Clin N Am 2:425-435, 1991
26. Thomas JE, Baker HL Jr: Assessment of roentgenographic lucencies of the skull: a systematic approach. Neurology 25:99-106, 1975

27. Uemura K, Tsuboi K, Nose T: Intradiploic hematoma. AJNR Am J Neuroradiol 18:397-398, 1997

28. van Tellingen V, Obihara CC, van Tilborg GF, van Dijken PJ: MRI diagnosis of occipital cephalohematoma mimicking an encephalocele. Am J Perinatol 25:153-155, 2008

29. Wong CH, Foo CL, Seow WT: Calcified cephalohematoma: classification, indications for surgery and techniques. J Craniofac Surg 17:970-979, 2006

30. Yoon SD, Cho BM, Oh SM, Park SH: Spontaneous resorption of calcified cephalhematoma in a 9-month-old child: case report. Childs Nerv Syst 29:517-519, 2013

\section{Disclosures}

The authors report no conflict of interest concerning the materials or methods used in this study or the findings specified in this paper.

\section{Author Contributions}

Conception and design: Frassanito, Tamburrini, Caldarelli, Massimi. Acquisition of data: Battaglia, Frassanito, Massimi. Analysis and interpretation of data: Battaglia. Drafting the article: Massimi. Critically revising the article: Vigo, Tamburrini, Caldarelli, Massimi. Reviewed submitted version of manuscript: Vigo, Tamburrini, Caldarelli, Massimi.

\section{Correspondence}

Vera Vigo, Institute of Neurosurgery - A. Gemelli Hospital, Largo A. Gemelli, 8, Rome 00168, Italy. email: vera.vigo@gmail. com. 